\title{
Application of Copper Cladding Aluminum Composites in UHV Portable Earthing and Short-circuiting Wires
}

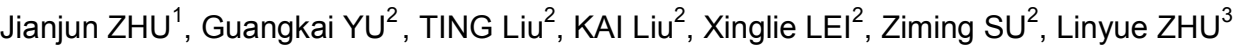 \\ ${ }^{1}$ State Grid Corporation of China, 100031 Beijing, China. \\ ${ }^{2}$ China Electric Power Research Institute, 430074 Wuhan, China. \\ ${ }^{3}$ Beijing NO.161 High School, Beijing 100031, China.
}

\begin{abstract}
Aiming at the heavy weight and inconvenience when carrying and installing copper earthing wires on the UHV transmission lines, in this paper, we present the use of copper clad aluminum(CCA) composite materials as a lightweight method for UHV earthing wire conductor. Theoretical calculations and tests of the fusing current in a short time for copper and CCA material are conducted. The results show that the theoretical value of the earthing wire conductor's fusing current corresponds with the test value on condition of the conductor cross section greater than $4 \mathrm{~mm}^{2}$ as well as fusing time less than $1.5 \mathrm{~s}$. The CCA-10 earthing wires get $36.2 \%$ weight reduction compared with copper wires.
\end{abstract}

\section{Introduction}

UHV power transmission has the advantages of large transmission capacity, long distance of power transmission, low wire loss and less land occupation and other outstanding advantages. It is a kind of advanced power transmission technology with resource saving and environment friendliness. With the rapid development of China's UHV power grid, it has higher requirements for the practicality, convenience and safety of UHV special safety tools [1-2]. As a "save line" in the electrical maintenance operation, the earthing wire need to ensure the reliable connection between the maintenance equipment and the earth during the operation at the same time, and it should also be easy to carry and install by the operating personnel[3-4]. Conventional earthing wire conductors use the conventional soft copper stranded wire[5]. While UHV system has high voltage level, if it use the traditional material, the size and weight of UHV earthing wire would double increase compared with the conventional earthing wire. So in field use, it could not be carried and installed by the single person and it would require more manpower and take longer time to install a group of earthing wire, which greatly reduce the maintenance efficiency. Therefore, it is of great significance to develop a light ground lead suitable for overhauling of UHV lines.

In order to guarantee that the earthing wire would not fuse when the circuit is misoperated and electrified, the rated short-circuit current value of the earthing wire at the rated short-circuit time should be less than its fusing current value and the appropriate margin should be left[6]. In regards to the calculation of the wire fuse current,
Onderdonk formula of fusing current calculation of the copper material is provided by the domestic standard SSD332-89 [7] and the American standard ASTM F855$15[8]$; in IEC standard 61230[9], the relation curve between the current density, time and temperature rise of copper, aluminum, silver, steel and other different materials is provided; in the document[10-12], the electric heating fusing in rapid temperature rise and slow temperature rise of the wire is studied theoretically and experimentally. For the copper wire with diameter of 1.6 $\mathrm{mm}$, when the current duration is less than $100 \mathrm{~s}$, the law of the fusing current and time is basically in accordance with the calculation model of the adiabatic process; in the document[13], the change law of the conductor resistance in the conductor fusing process is studied.

In regards to the material of the earthing wire conductor, the US standard ASTM F855-15[8] only stipulates to use the copper wire. The domestic standard DL/T879-2004[14] mentions that the aluminum wire could be used, but any performance parameter requirement is not given. IEC standard 61230[9] stipulates that the earthing wire could use copper, aluminum or aluminum alloy conductor and the aluminum wire should be careful to use and save. Copper clad aluminum (CCA) is a new type of material that enabled a strong metallurgical bonding of copper layer and aluminum layer at the interface. It not only has high electrical conductivity and thermal conductivity of copper, but also has the low density and low price of aluminum[15-16]. CCA has been widely used in highfrequency signal transmission, power transmission as a transmission conductor [17-18]. 
Table 1. Characteristic comparison of soft pure copper, pure aluminum and CCA.

\begin{tabular}{|c|c|c|c|c|c|c|}
\hline \multirow{2}{*}{\multicolumn{2}{|c|}{$\frac{\text { Wire type }}{\text { Wire model[20-22] }}$}} & \multirow{2}{*}{$\begin{array}{c}\begin{array}{c}\text { Annealed } \\
\text { copper wire }\end{array} \\
\mathrm{TR}\end{array}$} & \multirow{2}{*}{$\begin{array}{c}\begin{array}{c}\text { Annealed } \\
\text { aluminum wire }\end{array} \\
\text { LR }\end{array}$} & \multicolumn{3}{|c|}{ Annealed CCA } \\
\hline & & & & CCA-10A & CCA-15A & CCA-20A \\
\hline \multirow{2}{*}{$\begin{array}{l}\text { Structure } \\
\text { parameter }\end{array}$} & $\begin{array}{l}\text { Volume ratio of } \\
\text { copper layer(\%) }\end{array}$ & 100 & 0 & 10 & 15 & 20 \\
\hline & $\begin{array}{c}\text { Minimum } \\
\text { wiredrawing } \\
\text { diameter(mm) }\end{array}$ & 0.02 & 0.3 & 0.08 & 0.08 & 0.08 \\
\hline \multirow{3}{*}{$\begin{array}{l}\text { Physical } \\
\text { property }\end{array}$} & $\operatorname{Density}\left(\mathrm{g} / \mathrm{cm}^{3}\right)$ & 8.93 & 2.70 & 3.32 & 3.63 & 3.95 \\
\hline & Melting point $\left({ }^{\circ} \mathrm{C}\right)$ & 1083 & 660 & $1083 / 660$ & $1083 / 660$ & $1083 / 660$ \\
\hline & $\begin{array}{l}\text { Specific heat } \\
\left(\mathrm{J} \cdot \mathrm{kg}^{-1} \cdot{ }^{\circ} \mathrm{C}^{-1}\right)\end{array}$ & 385.2 & 889.5 & 754.0 & 703.6 & 661.3 \\
\hline \multirow{2}{*}{$\begin{array}{l}\text { Electrical } \\
\text { properties }\end{array}$} & $\begin{array}{l}\text { Specific resistance } \\
\text { below } 20^{\circ} \mathrm{C}(\Omega \cdot \mathrm{m})\end{array}$ & $1.724 \times 10-8$ & $2.83 \times 10-8$ & $2.66 \times 10-8$ & $2.58 \times 10-8$ & $2.51 \times 10-8$ \\
\hline & $\begin{array}{c}\text { Temperature } \\
\text { coefficient of } \\
\text { resistance }\left(1 /{ }^{\circ} \mathrm{C}\right)\end{array}$ & $3.93 \times 10-3$ & $4.29 \times 10-3$ & $4.23 \times 10-3$ & $4.21 \times 10-3$ & $4.19 \times 10-3$ \\
\hline \multirow{3}{*}{$\begin{array}{l}\text { Mechanical } \\
\text { property }\end{array}$} & $\begin{array}{c}\text { Strength of } \\
\text { extension (MPa) }\end{array}$ & $220-270$ & $70-100$ & $130-170$ & $130-170$ & $130-170$ \\
\hline & $\begin{array}{c}\text { Elongation at break } \\
(\%)\end{array}$ & $30-45$ & $23-25$ & $25-30$ & $25-30$ & $25-30$ \\
\hline & $\begin{array}{c}\text { Elastic modulus } \\
(\mathrm{MPa})\end{array}$ & 120000 & 63000 & 69000 & 72000 & 75000 \\
\hline
\end{tabular}

This paper proposed light scheme of UHV earthing wire where copper clad aluminum stranded wire replaced the existing copper wire. The dimension parameters of earthing wire of copper and copper clad aluminum materials are determined and the weight loss effect of copper-clad aluminum composite material is verified quantitatively.

\section{Characteristics of copper clad aluminum composite wire}

Copper clad aluminum composite wire is made of longitudinal seam welding through copper strips, blank drawing and annealing process[19] after the aluminum rod covered the pure copper strip. Now soft copper clad aluminum wire characteristics parameter after the annealing process is compared with the soft copper wire and soft aluminum wire as shown in Table 1. It could be seen from the table that the characteristics of the copper clad aluminum composite wire is between the copper and aluminum and is related with the content ratio of copper and aluminum. When the volume ratio of copper layer increases, the conductivity and mechanical strength of the composite wire is higher, while the weight also increases accordingly.

\section{Calculation and test of instantaneous fusing current of the earthing wire con- ductor material}

\subsection{Promotion algorithm of Onderdonk formula}

\subsubsection{Derivation of onderdonk formula for copper material}

The use of copper clad aluminum composite wire as UHV earthing wire conductor has small density compared to the pure copper wire while it has higher electrical and mechanical property than the pure aluminum wire. In addition, the current copper earthing wire is usually made of monofilament stranded wire with diameter of $0.1-0.2 \mathrm{~mm}$, which has good flexibility and is easy to coil and bend when being stored and carried; while the pure aluminum has poor flexibility, and the diameter of monofilament under the existing drawing process is no less than $0.3 \mathrm{~mm}$, and the strand is easy to break during stranding process, which affects the overall performance of the strand. After the use of aluminum alloy and modification, the flexibility and mechanical properties could be increased, the copper clad aluminum base after clad-welding could be made into soft state monofilament with diameter of $0.08 \mathrm{~mm}$ through the process of drawing and annealing and it could reach the flexibility the same as the copper stranded wire. The copper and aluminum atoms of the well processed copper clad aluminum composite wire penetrate each other in the copper and aluminum interface to form a solid compound layer[23], and even in the high temperature or greater pull force, it is not easy to have the interface separation, which has a stable structural characteristics.

According to the domestic standard SSD332-89[7] and the American standard ASTM F855-15[8], the fusing current of copper material carrying short-circuit earthing wire could be calculated by using Onderdonk formula:

$$
I_{m}=A \sqrt{\frac{\log \left(\frac{T_{m}-T_{A}}{234+T_{A}}+1\right)}{33 t}}
$$

In the formula (1), $\mathrm{I}_{\mathrm{m}}$ is the melting current value, $\mathrm{A}$; $A$ is the cross section of the earthing wire, the circular mil; $\mathrm{t}$ is the time to withstand the current, $\mathrm{s}$; $\mathrm{T}_{\mathrm{m}}$ is the melting 
temperature of the metal, ${ }^{\circ} \mathrm{C} ; \mathrm{T}_{\mathrm{A}}$ is the ambient temperature, ${ }^{\circ} \mathrm{C}$.

The formula is derived as follows:

As the duration of the short-circuit current is very short, the earthing wire and the external environment have very little heat exchange, which could be approximated as an adiabatic process. The Power loss generated by the short-circuit current all changed to thermal energy, and it leads to the temperature increase of the earthing wire. The first order differential equation could be listed between time $t$ and the unit length of the earthing wire:

$$
c \rho A \cdot d \theta(t)=\rho_{A}\left[1+\alpha_{A} \cdot \theta(t)\right]\left(I^{2} / A\right) \cdot d t
$$

In the formula (2), c is the specific heat capacity, $\rho$ is the mass density, $\mathrm{A}$ is the section area of the earthing wire, $\rho_{\mathrm{A}}$ is the conductor resistivity of the initial ambient temperature $T_{A} . \alpha_{A}$ is the resistance temperature coefficient, and $I$ is the effective value of the shortcircuit current . After (2) is simplified, it could be gained:

$$
\frac{d \theta(t)}{1+\alpha_{A} \cdot \theta(t)}=\frac{\rho_{A} I^{2}}{c \rho A^{2}} d t
$$

Integral both sides, after solving formula (3), it could be gained (make $\mathrm{t}=0, \theta(0)=0$; when $\mathrm{t}=\mathrm{t}, \theta(t)=\theta$ ):

$$
\ln \left(1+\alpha_{A} \cdot \theta\right)=\frac{\alpha_{A} \rho_{A} I^{2}}{c \rho A^{2}} \cdot t
$$

Formula (4) could be transformed to:

$$
\left(\frac{\alpha_{A} \rho_{A}}{c \rho}\right) \frac{I^{2}}{A^{2}} \cdot t=\ln \left(1+\frac{\theta}{1 / \alpha_{A}}\right)
$$

It is approximately to consider that when the original temperature is in certain range (for example $0-100^{\circ} \mathrm{C}$ ), $\alpha_{A} \rho_{A}$ is the constant value:

$$
\alpha_{A} \rho_{A}=\alpha_{20} \rho_{20}
$$

In formula (6), $\alpha_{20}, \rho_{20}$ are the temperature coefficient of the conductor resistance and the specific resistance at $20{ }^{\circ} \mathrm{C}$ respectively. For copper materials, they are:

$$
\begin{aligned}
& \alpha_{20}=0.00393\left(1 /{ }^{\circ} \mathrm{C}\right) \\
& \rho_{20}=1.724 \times 10^{-8}(\Omega \cdot \mathrm{m}) \\
& c=385.2\left[\mathrm{~J} /\left(\mathrm{kg} \cdot{ }^{\circ} \mathrm{C}\right)\right] \\
& \rho=8930\left(\mathrm{~kg} / \mathrm{m}^{3}\right)
\end{aligned}
$$

The value of formula (7) is put the left side of the formula (5), and it could be gained:

$$
1.97 \times 10^{-17} \frac{I^{2}}{A^{2}} \cdot t=\ln \left(1+\frac{\theta}{1 / \alpha_{A}}\right)
$$

The section area unit is converted to circular mil from square meter $(1 \mathrm{~m} 2=1.98 \times 109$ circ-miles $)$, and is changed to the usual logarithmic base, and it could be gained:

$$
33 \frac{I^{2}}{A^{2}} \cdot t=\log \left(1+\frac{\theta}{1 / \alpha_{A}}\right)
$$

In addition, it could be gained from formula (6)、(7) that:

$$
\begin{aligned}
1 / \alpha_{A} & =\rho_{A} /\left(\alpha_{20} \rho_{20}\right)=\left[\rho_{20}+\rho_{20} \cdot \alpha_{20}\left(T_{A}-T_{20}\right)\right] /\left(\alpha_{20} \rho_{20}\right) \\
& =\frac{1}{\alpha_{20}}+T_{A}-T_{20}=\frac{1}{0.00393}+T_{A}-20=234+T_{A}
\end{aligned}
$$

When formula (10) is put to formula (9), it could be gained that:

$$
33 \frac{I^{2}}{A^{2}} \cdot t=\log \left(1+\frac{\theta}{234+T_{A}}\right)
$$

When the wire temperature reaches the melting point $T_{m}$, the temperature rise is $\theta=T_{m}-T_{A}$. At this time, I is the maximum short-circuit current $I_{m}$, and it is taken into the formula (11), which could be gained that:

$$
33 \frac{I_{m}{ }^{2}}{A^{2}} \cdot t=\log \left(1+\frac{T_{m}-T_{A}}{234+T_{A}}\right)
$$

After formula (12) is transformed, formula (1) could be gained, ie the equation of Onderdonk. When using the copper earthing wire, take $\mathrm{T}_{\mathrm{m}}=1083^{\circ} \mathrm{C}$ (melting point of copper), $\mathrm{T}_{\mathrm{A}}=40^{\circ} \mathrm{C}$, and A (circular mil) is converted to $\mathrm{S}$ $\left(\mathrm{mm}^{2}\right)$, and the above formula could be simplified as:

$$
\mathrm{I}_{m}=283.7 \mathrm{~S}_{\mathrm{Cu}} / \sqrt{t}
$$

\subsubsection{Calculation of fusing current of copper clad aluminum composite material}

For pure aluminum material, it could be gained:

$$
\begin{aligned}
& \alpha_{20}=0.00429\left(1 /{ }^{\circ} \mathrm{C}\right) \\
& \rho_{20}=2.87 \times 10^{-8}(\Omega \cdot \mathrm{m}) \\
& c=889.5\left[\mathrm{~J} /\left(\mathrm{kg} \cdot{ }^{\circ} \mathrm{C}\right)\right] \\
& \rho=2703\left(\mathrm{~kg} / \mathrm{m}^{3}\right)
\end{aligned}
$$

According to the above method, the calculation formula of melting current of aluminum wire could be derived as follows:

$$
\mathrm{I}_{m(A l)}=A \sqrt{\frac{\log \left(\frac{T_{m}-T_{A}}{213+T_{A}}+1\right)}{87.2 t}}
$$

Take aluminum wire $\mathrm{T}_{\mathrm{m}}=660^{\circ} \mathrm{C}$, (melting point of aluminum), $\mathrm{T}_{\mathrm{A}}=40^{\circ} \mathrm{C}$ and convert $\mathrm{A}$ (circular mil) to $\mathrm{S}$ $\left(\mathrm{mm}^{2}\right)$, and the above formula could be simplified as:

$$
\mathrm{I}_{m}=155.5 \mathrm{~S}_{A l} / \sqrt{t}
$$

For CCA composite wire, since the compound layer at the interface of copper and aluminum is usually no more than $20 \mu \mathrm{m}[23]$, when calculating the fusing current, the impact of the interface layer and the thermal conductivity between the copper, aluminum layer during transient process could be ignored. For CCA wire whose copper layer volume ration is $15 \%$, ie, the copper, aluminum section area ratio of the wire is $\frac{S_{C u}}{S_{A l}}=\frac{15}{85}=0.176$. The skin effect is ignored and it is considered that the current and resistance flew through the copper layer and aluminum layer at the same time had inversed proportion: $\frac{I_{C u}}{I_{A l}}=\frac{R_{A l}}{R_{C u}}=\frac{\rho_{A l}^{\prime} / S_{A l}}{\rho_{C u}^{\prime} / S_{C u}}=\frac{1.724}{2.87} \div 0.176=3.4$ current through the wire is I, then:

$$
I_{C u}=0.23 I
$$




$$
I_{A l}=0.77 I
$$

Put formula (18) to formula (16), and the section area of aluminum layer is gained as followings:

$$
S_{A l}=\frac{0.77 I \sqrt{t}}{155.5}=\frac{I \sqrt{t}}{201.9}
$$

Then the section area of corresponding copper layer is:

$$
S_{C u}=S_{A l} \cdot 0.176=\frac{I \sqrt{t}}{1147}
$$

In addition, put formula (17) into the formula (13), and the flowing current could be gained to ensure the minimum section area of no fusing copper material:

$$
S_{C u}=\frac{0.23 I \sqrt{t}}{283.7}=\frac{I \sqrt{t}}{1233}
$$

After comparing (20)、(21), it could be gained that $S_{C u}^{\prime}<S_{C u}$. So when the short circuit current flew through $\mathrm{CCA}$, the aluminum material would fuse firstly. Put formula (18) and $S_{A l}=0.85 S$ to formula (16), the copper layer volume ration could be gained, which is the relationship between 15\% CCA fusing current and section area: $0.77 I_{m}=155.5 \times 0.85 S_{C C A-15} / \sqrt{t}$ :

$$
I_{m}=171.6 S_{C C A-15} / \sqrt{t}
$$

Similarly, fusing current calculation formula of the CCA wire with copper volume ratio of $10 \%$ and $20 \%$ could be derived:

$$
\begin{aligned}
& I_{m}=165.8 S_{C C A-10} / \sqrt{t} \\
& I_{m}=176.2 S_{C C A-20} / \sqrt{t}
\end{aligned}
$$

The reduction coefficient $\mathrm{K}$ (value is 1.08-1.15) [5] is introduced, and the rated short-circuit current of the earthing wire is:

$$
I_{r}=I_{m} / K
$$

The unit length weight $\mathrm{m}$ of the earthing wire conductor is:

$$
m=\rho S
$$

Put formula (24), (25) into the formula (13), (22) and (23), the rated short-circuit current Ir could be gained (unit: A). When the rated short-circuit time is t (unit: $s$ ), the unit length weight of copper and CCA earthing wire is:

$$
\begin{aligned}
& m_{C u}=3.15 \times 10^{-5} \mathrm{KI} r \sqrt{t}(\mathrm{~kg} / \mathrm{m}) \\
& m_{C C A-10}=2.01 \times 10^{-5} \mathrm{KI} r \sqrt{t}(\mathrm{~kg} / \mathrm{m}) \\
& m_{C C A-15}=2.12 \times 10^{-5} \mathrm{KI}, \sqrt{t}(\mathrm{~kg} / \mathrm{m}) \\
& m_{C C A-20}=2.24 \times 10^{-5} I_{r} \sqrt{t}(\mathrm{~kg} / \mathrm{m})
\end{aligned}
$$

It could be seen from the above formula that when the rated short-circuit current of the earthing wire is the same with the short circuit time, although the section area needed by CCA earthing wire is greater than the pure copper wire, the overall weight of earthing wire conductor decreases because CCA material density is much smaller than copper; the smaller the proportion of copper layer is, the more the weight reduces. The theoretical calculation showes that the section area of CCA wire with copper layer volume ratio of $10 \%$ is $71.1 \%$ larger than that of copper wire, but the weight could be reduced by $36.2 \%$.

\subsection{Test and analysis of fusing current}

\subsubsection{Test arrangement}

In order to further verify the fuse characteristics of CCA material in the instantaneous current and compare with the copper material, the copper of the different section and CCA-10 copper clad aluminum small strand samples are selected to carry out the fusing current test, and the test layout is shown below. The tested wire samples are applied the power frequency current through the high

\begin{tabular}{|c|c|c|c|}
\hline \multirow[b]{2}{*}{$\begin{array}{c}\text { Sample } \\
\text { Specification }\end{array}$} & \multirow{2}{*}{$\begin{array}{l}\text { Effective } \\
\text { value of test } \\
\text { current } \\
\text { (A) }\end{array}$} & \multicolumn{2}{|c|}{ Fusing time(s) } \\
\hline & & Test value & $\begin{array}{c}\text { Calculation } \\
\text { value }\end{array}$ \\
\hline \multirow{3}{*}{$\begin{array}{c}2.5 \mathrm{~mm}^{2} \\
\text { copper } \\
\text { stranded wire }\end{array}$} & 396 & 4.02 & 3.21 \\
\hline & 528 & 2.35 & 1.80 \\
\hline & 556 & 2.05 & 1.63 \\
\hline \multirow{3}{*}{$\begin{array}{c}4 \mathrm{~mm}^{2} \\
\text { copper } \\
\text { stranded wire }\end{array}$} & 424 & 7.24 & 7.16 \\
\hline & 575 & 4.12 & 3.89 \\
\hline & 650 & 3.24 & 3.05 \\
\hline \multirow{3}{*}{$\begin{array}{c}2.5 \mathrm{~mm}^{2} \\
\text { CCA } \\
\text { stranded wire }\end{array}$} & 100 & $\begin{array}{l}\text { Not fuse } \\
\text { for } 10 \mathrm{~s}\end{array}$ & 17.18 \\
\hline & 236 & 3.98 & 3.08 \\
\hline & 330 & 2.25 & 1.58 \\
\hline \multirow{3}{*}{$\begin{array}{c}4 \mathrm{~mm}^{2} \\
\text { copper } \\
\text { stranded wire }\end{array}$} & 377 & 3.56 & 3.09 \\
\hline & 490 & 2.10 & 1.83 \\
\hline & 556 & 1.54 & 1.42 \\
\hline
\end{tabular}
current generator of the power frequency, and the oscilloscope collected the voltage across of the shunt (micro-European rating resistor) thus to obtain the wire current waveform and fuse time and use the high-speed camera to record the whole process of wire sample fuse, and the test electrode spacing is $100 \mathrm{~mm}$.

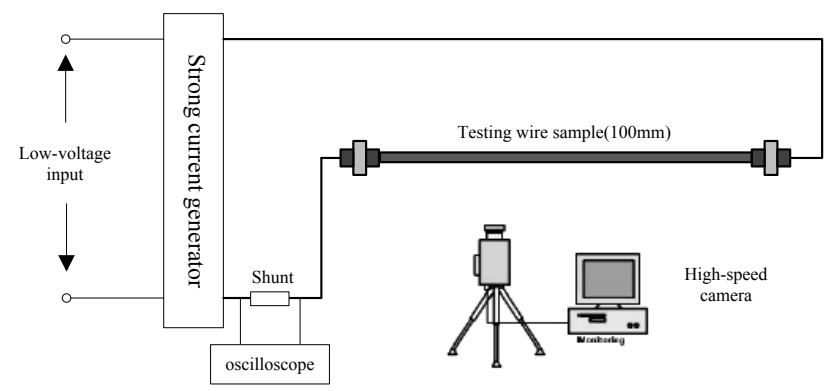

Figure 1. Layout diagram of fusing current test of earthing wire conductor material.

\subsubsection{Analysis of test results}

Table 2. Fusing current test results of copper and CCA stranded wire samples.

The fusing current test of $2.5 \mathrm{~mm}^{2}$ and $4 \mathrm{~mm}^{2}$ pure copper and CCA-10 copper clad aluminum composite wire is carried out respectively. The two wires are both stranded by the soft monofilament with diameter of 

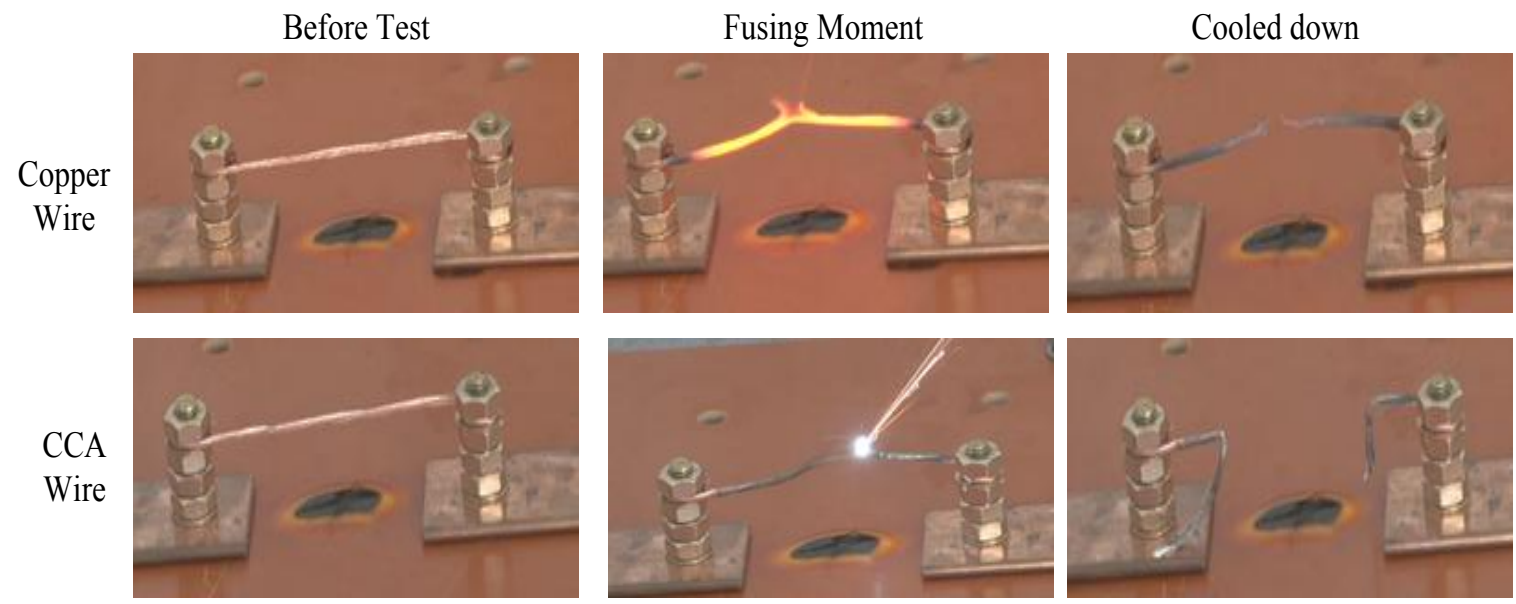

Figure 2. Layout diagram of fusing current test of earthing wire conductor material.
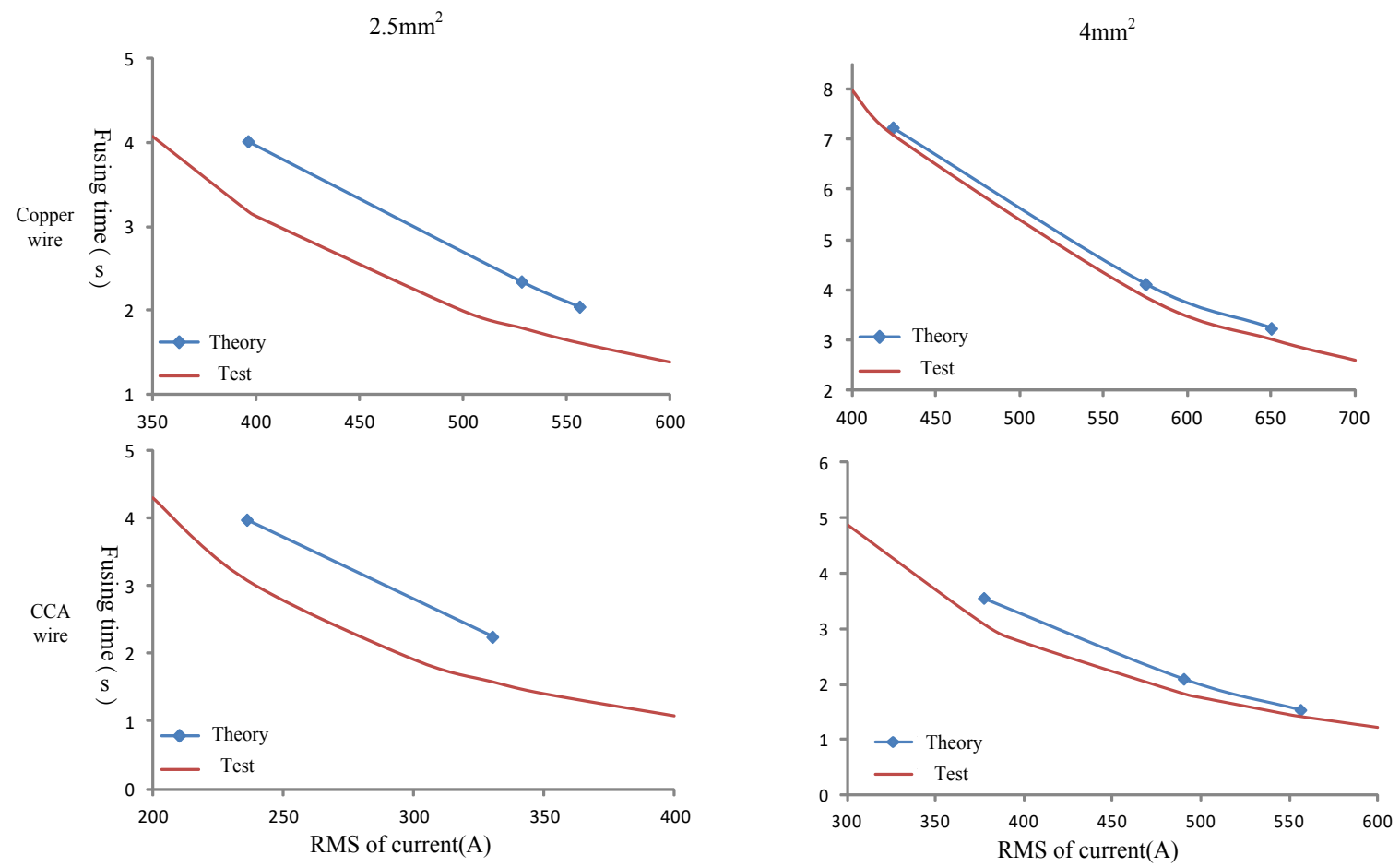

Figure 3. Comparison of fusing current test and theoretical calculation.

$0.2 \mathrm{~mm}$. By adjusting the output current, recording the fusing time in different currents, the test process and the results are shown in figure 2 , table 2 .

The experimental results are compared with the theoretical results in section 3.1, and the relation curve between the fusing time and the effective value of fusing current is shown in figure 3 . It could be seen from the figure that:

(1) If the effective values of the current which flew through the samples with the same material and section are the same, the fuse time obtained by the test is greater than the theoretical calculation value, which is because the heat exchange between the wire and the external environment is ignored and is regarded as an adiabatic process. While during the actual test, the insulation measures are not taken and part of the energy dissipated to the surrounding environment.
(2) The larger the section of the test sample, the smaller the average heat dissipation area, so the closer the test value is to the calculated value.

(3) The greater the test current is, the shorter the fusing time is, the smaller the dissipation heat is, so the closer the test value is to the calculated value.

(4) When the wire section is greater than $4 \mathrm{~mm} 2$ and the fusing time is less than $1.5 \mathrm{~s}$, the error between the test result and the calculated value is less than $10 \%$, and the influence of heat exchange with the surrounding environment could be neglected.

\section{Conclusion}

This paper put forward the use of copper clad aluminum(CCA) composite materials as a lightweight method for UHV earthing wire conductor. Theoretical calculations and tests of the fusing current in a short time 
for copper and CCA material are conducted. The following conclusions are drawn:

1)Copper clad aluminum composite material has the advantages of both high conductivity of copper and low density of aluminum. It is proposed to use copper clad aluminum to replace the traditional copper materials as high voltage earthing wire conductor.

2)By theoretical calculation, compared with copper earthing wire, the section area of CCA with copper layer volume ration of $10 \%$ increases $71.1 \%$, but the weight reduces $36.2 \%$.

3)Under the same time, the fusing current test result of the copper and CCA small stranded sample is higher than the theoretical calculated value under adiabatic conditions. When the wire section is larger than $4 \mathrm{~mm}^{2}$ and the fusing time is less than $1.5 \mathrm{~s}$, the error between the test result and calculation value is less than $10 \%$ and the heat exchange effect with the surrounding environment could be ignored.

\section{References}

1. LIU Zhenya. Innovation of UHVAC transmission technology in China[J]. Power System Technology, 2013, 37(3): 1-8.

2. LIU Zhenya. Ultra-high voltage AC \& DC grid[M]. Beijing, China: China Electric Power Press, 2013.

3. ZHAO Zhijun. Earthing and short-circuiting wires the survive lines in electrical maintenance.[J]Heilongjiang Science and Technology Information, 2008, (14): 30.

4. DAI Keming. Correct use of portable earthing and short-circuiting wires.[J]. Electric Safety Technology, 2011, 13(11): 20-24.

5. LI Jinxiong. Application of earthing and shortcircuiting devices[M]. Beijing, China: China Electric Power Press, 2008.

6. ZHU Zhongming. The discussion of rated shortcircuit current for portable earthing and shortcircuiting wires $[\mathrm{J}]$. East China Electric Power, 1994, (10): 23-25.

7. SSD332-89. Technical standard of portable earthing and short-circuiting wires[S]. Beijing, China: China Standard Press, 1989.

8. ASTM F855-15. Standard specifications for temporary protective grouds to be used on deenergized electric power lines and equip-ment[S]. 2015.
9. IEC 61230:2008. Live working - Portable equipment for earthing and short-circuiting[S]. 2008.

10. Babrauskas V, Wichman I S. Fusing of wires by electrical current $[\mathrm{C}]$. Fire and Materials 12th International Conference and Exhibition, San Francisco, USA: Interscience Communications, 2011: 769-778.

11. Choi C S, Kim H K, Kim D W, et al. Analysis of dispersive characteristics and structures of copper wire melted by overcurrent[J], IEEJ Trans, 2005, 125(12): 1327-1331.

12. Wright A, Newbery P G. Electric fuses[M], 3rd ed. Stevenage, UK: Institution of Electrical Engineers, 2004: 191-194.

13. Tanaka T, Yamasaki M. Modeling of fuses for melting time and fusing current analysis[C]. Telecommunications Energy Confer-ence(INTLEC), Chicago, USA: IEEE, 2004: 671-675.

14. DL/T 879-2004. Portable equipment for earthing and short-circuiting for live working[S]. Beijing, China: China Standard Press, 2004.

15. Gibson A. The economics of copper clad aluminum bometallic cables[J]. Wire \& Cable Technology International, 2005, 33(4): 82-83.

16. ZHANG Jianyu, YAO Jinjin, ZENG Xiangyong, et al. Research progress of copper cladding aluminum composites[J]. The Chinese Journal of Nonferrous Metals, 2014, 24(5): 1275-1284.

17. SHOU Weichun, LI Xiangli. The application of CCA wire in coaxial cable[J]. Optical Fiber \& Electric Cable, 2000(2): 40-45.

18. DONG Yongjun, WANG Jianwei, HUANG Chunde, et al. Ther-modynamic equilibrium calculation of copper clad aluminum composite[J]. Chinese Journal of Rare Metals.

19. ZHENG Chuantao, DAI Yakang. The characteristics of copper clad aluminum wire effect on the service performance of copper clad aluminum cable[J]. Electic Wire \& Cable, 2016, (6): 4-7.

20. GB/T 3953-2009. Round copper wire for electrical purposes[S] Beijing, China: China Standard Press, 2009.

21. GB/T 3955-2009. Round aluminum wire for electrical purposes[S] Beijing, China: China Standard Press, 2009.

22. GB/T 29197-2012. Copper-clad aluminum wire[S] Beijing, China: China Standard Press, 2012.

23. ZHAO Zhengshu, DAI Yakang. Study of copper clad aluminum wire annealing technology[J] Electic Wire \& Cable, 2011, (6): 6-8, 23. 